\title{
Occipito-Frontal Circumference as a Personal Stature Predictor in a Group of Sri Lankan Adults
}

\author{
Circunferencia Occipito-Frontal como Predicción de la Estatura \\ en un Grupo de Adultos de Sri Lanka
}

I. Ilayperuma; B. G. Nanayakkara \& N. K. Palahepitiya

ILAYPERUMA, I.; NANAYAKKARA, B. G. \& PALAHEPITIYA, N. K. Occipito-frontal circumference as a personal stature predictor in a group of Sri Lankan adults. Int. J. Morphol., 35(4):1316-1321, 2017.

SUMMARY: Accurate estimation of the personal stature is important in calculating body mass index, assessing nutritional status and the risk of cardiovascular disease, prediction of energy needs and in adaptation of cytostatic drug doses. However, various situations such as, patients in emergency or critical care settings or immobilized patients who are bed ridden or in wheelchairs make it difficult or even impossible to obtain the personal stature using standardized methods. Thus, the need for an alternate method of personal stature prediction arises. Despite its potential practical utility, little is known concerning the relationship between occipito-frontal circumference (OFC) of the head and personal stature among the adult Sri Lankans. Therefore, the goal of this study was to propose population and sex specific regression formula for personal stature estimation using the OFC. Personal stature and OFC was recorded in a total of 156 cadavers belonging to 55 - 89 years of age: (male: $n=74$; female: $n=82$ ). Subjects with any craniofacial deformities or history of neurological disorders were excluded from the study. The mean stature (cm) (male:162.08 $\pm 9.02 ;$ female:157.04 \pm 9.59$)$ and OFC $(\mathrm{cm})$ (male: $54.09 \pm 3.28$; female: $52.88 \pm 2.83$ ) of the study subjects were found to be significantly different $(\mathrm{P}<0.01)$ between the sexes. Correlation coefficient between the OFC and personal stature was statistically significant and positive in both males (0.62) and females (0.86) indicating a strong relationship between the two parameters. Linear regression formulae for the prediction of personal stature using the OFC were derived as follows: male: $70.52+1.69$ (OFC); female: $3.48+2.92$ (OFC). Stature prediction equations that require a measuring tape as the only tool to record the OFC provides a practical alternative for the height estimation of patients who are unable to stand due to various reasons. It is a simple, cost effective, non invasive and objective method for personal stature prediction. Accurate prediction of a patient's stature will in turn, reduce potential errors that may occur when stature is estimated only by visual observation in emergency or clinical situations. Complementary studies are necessary to evaluate the applicability of these equations in other age groups too.

KEY WORDS: Occipito-frontal circumference; Stature; Sri Lankans.

\section{INTRODUCTION}

Personal stature is an important anthropometric measurement in calculating body mass index of an individual, assessing nutritional status and the risk of cardiovascular disease and type 2 diabetes (Herout \& Erstad, 2004; Bays et al., 2007), estimation of body composition by bioimpedance analysis and prediction of energy needs. In addition, personal stature also forms the basis for the adaptation of cytostatic drug doses through the calculation of body surface area (Kouno et al., 2003).

There are many instances where precise personal stature of a patient is practically difficult or impossible to obtain using standardized methods. For example, in immobilized patients who are bedridden or in wheelchairs, patients who are affected by deformities of the vertebral column such as scoliosis or kyphosis, or in emergency settings when patients are unable to stand on a scale to be measured accurately or clearly state their height due to altered mental status (Rabito et al., 2006). Consequently, various studies have proposed obtaining personal stature through prediction formulas based on various anthropometric variables such as arm-span (Haboubi et al., 1990; Kwok \& Whitelaw, 1991), half arm-span (Bassey, 1986), knee height (Chumlea et al., 1985) and cranial dimensions in different populations (Chiba \& Terazawa, 1998; Krishan, 2008; Ilayperuma, 2010). 
Head circumference or the occipito-frontal circumference (OFC) is the greatest of the cranial dimensions which passes around the forehead anteriorly and the external occipital protruberance posteriorly (Williams et al., 2000; Krishan). It is a routine part of the physical examination of a child and is of great importance in detecting abnormal patterns of cranial growth (Harper et al., 1984).

Evidence shows a clear racial trend in the cranial dimensions and cephalic indices among different populations such as, Caucasians, Indians, Turkman and native Farsgroups, Kosov and Albanians, Iranians, Japanese, Serbs, Greek, Bulgarians, Mapuche individuals in Chile, Nigerians, Caucasians and Sri Lankans (Okupe et al., 1984; Obikili \& Singh, 1992; Kasai et al., 1993; Abolhasanzadeh \& Farahani, 2003; del Sol, 2005; Rexhepi \& Meka, 2008; Ilayperuma, 2011). Therefore, knowledge on the cranial morphometry is important in the study and comparison of the crania of populations from different racial, geographic and dietary backgrounds. Such information is also useful in studies of primate phylogeny. In clinical practice, population and age specific data on cranial dimensions gives an indication of the growth and development of an individual and also any abnormalities of cranial size and shape (Harper et al.).

As the cranial dimensions are influenced by the race, sex and age of an individual, the need for race, age and sex specific formulae is also proved beyond doubt (Krishan). It is important that predictive formulas are valid for a particular population in which they will be used so that the equations cover the characteristics of that population.

Despite its significance and potential practical utility, little is known concerning the relationship between head circumference and personal stature among adult Sri Lankans, inhabitants of the South Asian country. Hence, the goal of this study was to propose population and gender specific regression models for stature estimation using the occipitofrontal circumference of the head.

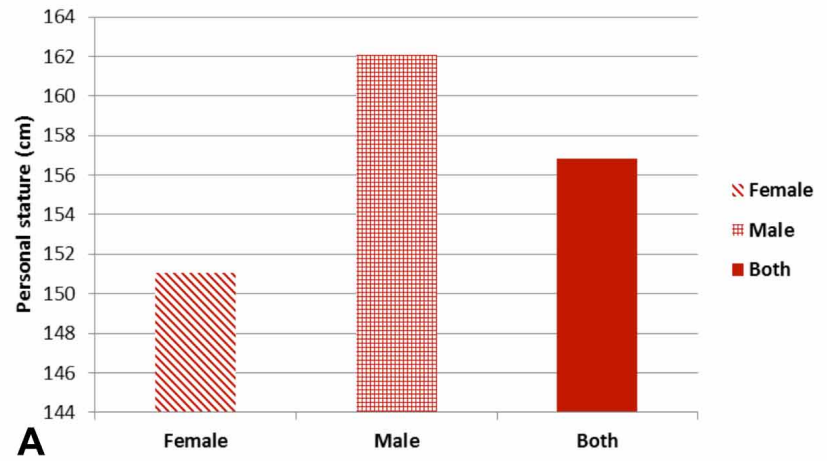

\section{MATERIAL AND METHOD}

This study was conducted on total of 156 cadavers donated to the Department of Anatomy, Faculty of Medicine, University of Ruhuna, Sri Lanka. Only the subjects without any craniofacial or vertebral column deformities were included in the study. All the study subjects were belonging to the same ethnic group and they were from different parts of the island belonging to different socioeconomic status. The age of the subjects ranged from 55 89 years.

The personal stature was recorded as the straight distance between vertex of the skull and the heel of the foot. Head circumference data were recorded as the maximum circumference of the head measured from just above the glabella to the area near the top of the occipital bone (opisthocranion) (Krishan). Both measurements were taken using a flexible steel measuring tape capable of measuring to the nearest $0.1 \mathrm{~cm}$. All the measurements were recorded at a fixed time between $14.00-16.30$ hours to eliminate discrepancies due to diurnal variation. All the measurements were repeated thrice and the mean was taken for further analysis. Furthermore, the measurements were recorded by the same person to minimize the errors in methodology.

Results were expressed as mean \pm SD and analyzed using the Statistical Package for Social Sciences (SPSS), 15 th version. A comparison of the mean values between the genders was performed using the t-test. $\mathrm{P}$ value $<0.01$ was considered statistically significant. The strength of association between the head circumference and personal stature was measured by the Pearson's correlation coefficient. Equations for stature estimation were obtained by linear regression analysis.

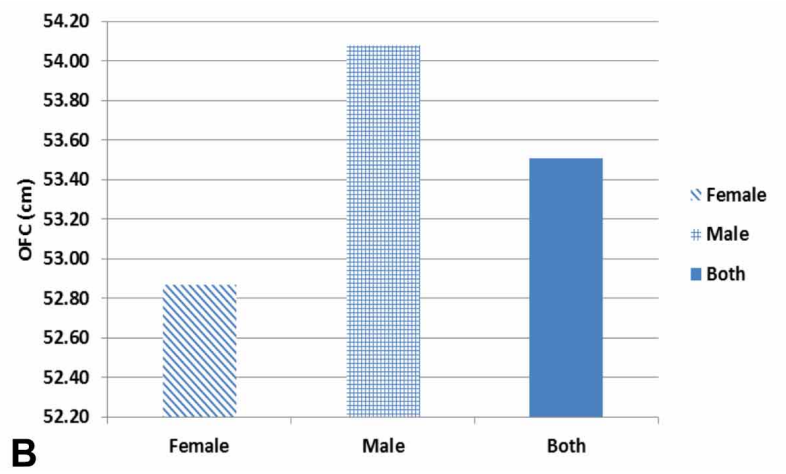

Fig. 1. A. Sex differences in personal stature. B. Sex differences in OFC. 


\section{RESULTS}

The mean ages of the study subjects (male: $75.49 \pm$ 7.69; female: $74.66 \pm 5.091)$ were not significantly different between the sexes (Table I). Sex differences with respect to personal stature and occipito-frontal circumference was found to be significantly larger in males compared to females $(\mathrm{P}<0.01)$ (Table I, Figs. 1A \& 1B).

A linear regression analysis was performed for estimation of personal stature using the OFC as an independent variable. Pearson's correlation coefficient was used to examine the relationship between $\mathrm{OFC}$ and perso- nal stature according to the sex. Correlation coefficient between the personal stature and OFC was found to be statistically significant and positive in both males $(0.62)$ and females (0.86). Scatter plots and linear regression lines demonstrating the relationship between personal stature and OFC are illustrated in Figures 2A, B \& C. Linear regression formula for the prediction of stature using head circumference were derived as follows:

Regression equation for prediction of stature from OFC:

For male: $70.52+1.69(\mathrm{OFC})$;

For female: $3.48+2.92$ (OFC);

For both male and female (combined): $25.91+2.45(\mathrm{OFC})$.
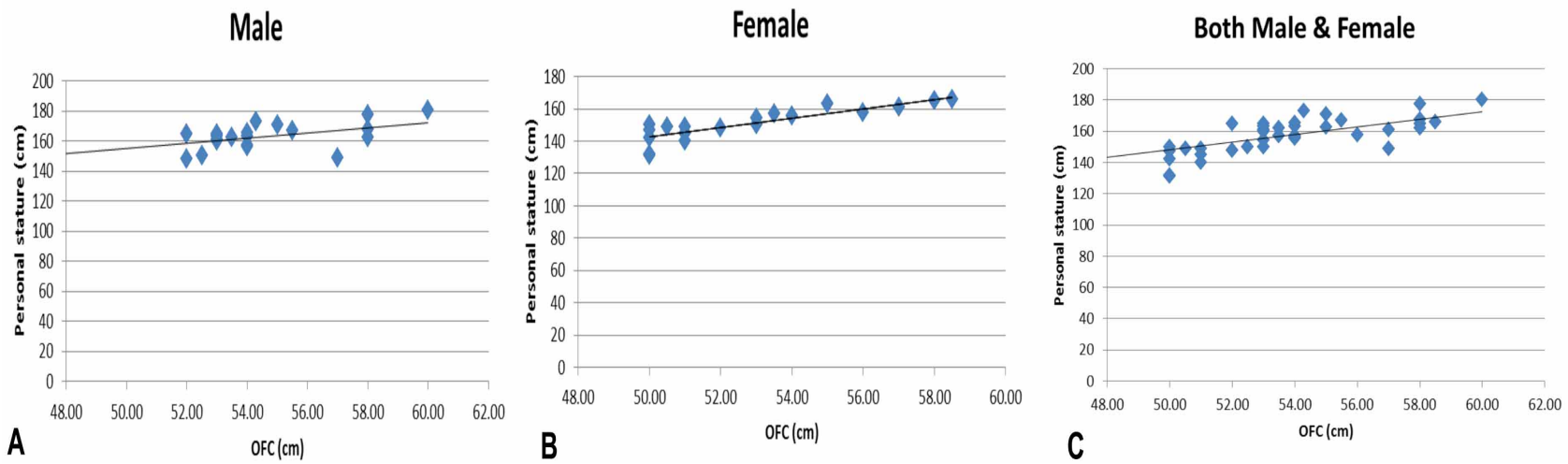

Fig. 2. A. Scatter plot and regression line demonstrating the relationship between personal stature and OFC (cm) in males. B. Scatter plot and regression line demonstrating the relationship between personal stature and OFC $(\mathrm{cm})$ in females. C. Scatter plot and regression line demonstrating the relationship between personal stature and $\mathrm{OFC}(\mathrm{cm})$ in both males and females.

Table I. Characteristics of the study subjects.

\begin{tabular}{lccc}
\hline Parameter & Female & Male & Both \\
\hline Total Number & 74 & 82 & 156 \\
Age range (years) & $68-83$ & $55-89$ & $55-89$ \\
Mean age (years) & $74.66 \pm 5.09$ & $75.49 \pm 7.69$ & $75.10 \pm 47.13$ \\
Body height range $(\mathrm{cm})$ & $165.7-131$ & $180.5-145$ & $180.5-145$ \\
Mean body height $(\mathrm{cm})$ & $157.04 \pm 9.59$ & $162.08 \pm 9.02 *$ & $156.84 \pm 10.79$ \\
OFC range $(\mathrm{cm})$ & $58.5-50$ & $60-43.2$ & $60-43.2$ \\
Mean OFC $(\mathrm{cm})$ & $52.88 \pm 2.83$ & $54.09 \pm 3.28^{*}$ & $53.51 \pm 3.13$ \\
\hline
\end{tabular}

$* \mathrm{P}<0.01$

\section{DISCUSSION}

The present study provides updated data pertaining to the occipito-frontal circumference of the head and its correlation with the personal stature in an adult group of Sri Lankan population. The current findings highlight the importance of taking into consideration the personal stature together with the OFC as structural characteristics evolve with age both during development and adulthood.
Several rare conditions have been identified where macrocephaly persists into adulthood: Cowden disease, tuberous sclerosis, neurofibromatosis type 1, Weaver syndrome, Sotos syndrome, autism spectrum disorder (Winter \& Baraitser, 1996; Williams et al., 2008; Nguyen et al., 2012). It is also important to note that adult patients with autism spectrum disorder displayed a statistically 
significant increase in OFC relative to norms (Nguyen $e t$ $a l$. .). Therefore, measurements of OFC play a vital role in the diagnosis of such conditions in adulthood (McCaffery \& Deutsch, 2005). In addition, some of these syndromes, like tuberous sclerosis and neurofibromatosis type 1 have an adulthood age of onset which further emphasizes the need for adult head circumference normative data (Nguyen et al.). Furthermore, it is stated that approximately $50 \%$ of normal head size variation is familial. Therefore adjustment of a child's head size value by the average parental value permits more refined assessment of head size when there is a suspected abnormality (McCaffery \& Deutsch).

It is generally assumed that stature remains proportional to the OFC. The relationship between personal stature and OFC in a given population will be a helpful indicator in depicting syndromes with a larger head in relation to stature (relative macrocephaly) (Saunders et al., 2006). The ability to accurately recognize relative abnormalities of head size serves in delineation of syndromes, diagnosis, and investigation of the causes. The results of the current study shows a positive correlation between personal stature and OFC, which suggest that absolute measurements of OFC without regard to stature are inadequate for demonstrating clinically significant abnormalities of head size (Ormeci et al., 1997).

In cancer chemotherapy, the doses of most chemotherapeutic agents are generally calculated using the body surface area which utilizes the body height. The same dose of anticancer agents will have different pharmacokinetics and pharmacodynamics due to individual variation in metabolizing and elimination of drugs. In addition, most anticancer agents have a narrow therapeutic index. Thus reducing the dose of these agents not only reduces toxicity but also the effects on the tumor. The importance of deciding the appropriate dose of anticancer agents cannot be overemphasized (Kouno et al.).

Several crucial decisions in emergency and critical care management of the patients, with regards to cardiac output, tidal volume settings, drug dosing, and calculation of nutritional goals rely on accurate measurement of personal stature. Further, body mass index, which directly relies on the stature, is an important predictor of mortality in the critically ill patient (Venkataraman et al., 2015). From a purely nutrition point of view, the formula used for calculating the basal metabolic rate directly relies on the stature. Thus it has been shown that, even a $1 \mathrm{~cm}$ error in stature estimation will contribute to a 6 times gross under or over estimation of the caloric requirement (Venkataraman et al.).
However, accurate personal stature is practically not feasible to measure in the critical care settings with the patients in the supine position and many life saving procedures intact thus restricting the access to the whole body (Venkataraman et al.). In addition, it is not clear how stature measurements should be interpreted in people who have experienced height loss due to conditions such as kyphosis or scoliosis. Therefore, visual estimations of patients' heights are popularly used for this purpose. It is important to note that, evidence shows that such visual estimations are often inaccurate and the discrepancies in visual estimation and actual stature in patients (Coe et al., 1999). Therefore, the need for alternative methods for stature estimation remains unfulfilled. A previous study showed that arm span was not a reliable method of height assessment among people of African and Asian ethnicity (Venkataraman et al.). This emphasizes the importance of standardizing height measurement methods unique for Sri Lankans.

The mean OFC for males observed in this study were greater than those observed for north Indians (Krishan) whereas it was smaller than in Canadians (Nguyen et al.), a finding that further reinforces the racial diversity in the OFC. It is speculated that such population diversity in cranial morphometry are attributed to race, age and geographical factors (Krishan).

Although variety of methodologies have been proposed to predict stature from various bones, regression analysis proved to be the easiest and the most reliable method (Krishan). Correlation coefficients between the personal stature and OFC among Sri Lankans were found to be statistically significant and positive ( 0.62 in male and 0.86 in female) indicating a strong relationship between the two parameters. Previous studies have shown correlation coefficients of 0.78 in North Indian males (Krishan), 0.44 in Nepalese male and 0.32 Nepalese females 0.32 (Mansur et al., 2014), 0.4 in Bangladesh male and 0.3 in Bangladesh female (Akhter et al., 2009). 0.34 in Canadian male (Nguyen et al.).

It is interesting to note that, when taking into account the correlation coefficient values between other cranial dimensions (cranial width, length \& height) and personal stature among Sri Lankans, OFC was found to be better than the cranial breadth and auricular head height in estimating male individual's stature whereas OFC was the best stature predictor out of all the cranial dimensions in a female (Ilayperuma, 2010). This observation was compatible with that of Indian population (Krishan).

Variety of factors such as, age, race, sex and nutritional status affect human development and growth and 
therefore, different nomograms are required for different populations (Williams et al., 2000). The present study for the first time documents such norms for OFC and presents sex specific linear regression models for stature prediction in an adult Sri Lankan population. These formulae are valid for the Sri Lankan subjects belonging to the age group of 68 -83 years. It is widely accepted that cranial morphology varies with the age of an individual (Wolf et al., 2003). In addition the height is also shown to progressively decrease with advancing age due to spinal cord shrinkage (Williams et al., 2000). The population, sex and age specific regression models proposed will be of immense practical use in clinical, medico-legal, anthropological and archeological studies where the personal stature of a subject can be calculated if the head circumference is known.

ILAYPERUMA, I.; NANAYAKKARA, B. G. \& PALAHEPITIYA, N. K. Circunferencia occipito-frontal como predicción de la estatura en un grupo de adultos de Sri Lanka. Int. J. Morphol., 35(4):1316-1321, 2017.

RESUMEN: La estimación precisa de la estatura es importante para calcular el índice de masa corporal, evaluar el estado nutricional, como también el riesgo de enfermedad cardiovascular, las necesidades energéticas y la adaptación de las dosis de los fármacos citostáticos. Sin embargo, varias situaciones, por ejemplo en situaciones de emergencias médicas o cuidados intensivos, los pacientes inmovilizados en cama o en silla de ruedas, se hace difícil o incluso imposible obtener la estatura usando métodos estandarizados. Por lo tanto, surge la necesidad de un método alternativo de predicción personal de la estatura. A pesar de su potencial utilidad práctica, se sabe poco sobre la relación entre la circunferencia occipito-frontal (COF) de la cabeza y la estatura entre los adultos de Sri Lanka. El objetivo de este estudio fue proponer una fórmula específica para la estimación de la estatura de acuerdo a población y sexo utilizando la COF. La estatura individual y la COF se registraron en un total de 156 cadáveres pertenecientes a individuos de 55-89 años de edad (hombre: $\mathrm{n}=74$, mujer: $n=82$ ). Los sujetos con deformidades craneofaciales o antecedentes de trastornos neurológicos fueron excluidos del estudio. Se encontró que la estatura media (cm) (varón: 162,08 \pm 9,02, mujer: $157,04 \pm 9,59)$ y OFC (cm) (hombre: 54,09 $\pm 3,28$, mujer: 52,88 \pm $2,83)$ era significativamente diferente $(\mathrm{P}<0,01)$ entre los sexos. El coeficiente de correlación entre la COF y la estatura fue estadísticamente significativo y positivo tanto en varones $(0,62)$ como en mujeres $(0,86)$, lo que indica una fuerte relación entre los dos parámetros. Las fórmulas de regresión lineal para la predicción de la estatura utilizando la COF se obtuvieron de la siguiente manera: hombres: 70,52 + 1,69(COF); mujeres: 3,48+2,92 (OFC). Las ecuaciones de predicción de la estatura que requieren una cinta métrica como la única herramienta para registrar la COF proporcionan una alternativa práctica para estimar la altura en aquellos pacientes que no pueden ponerse de pie por diversos motivos. Es un método sencillo, rentable, no invasivo y objetivo para la predicción personal de la estatura. La predicción exacta de la estatura del paciente, a su vez, reducirá los errores potenciales que pueden ocurrir cuando la estatura se estima sólo por observación visual en situaciones de emergencias o clínicas. Estudios complementarios son necesarios para evaluar la aplicabilidad de estas ecuaciones en otros grupos de edad.

PALABRAS CLAVE: Circunferencia occipito frontal; Estatura; Sri Lanka.

\section{REFERENCES}

Abolhasanzadeh, A. \& Farahani, M. R. Standard international classification of head shapes of 22-24 years old in Tehran. J. Res. Med., 26(4):281-5, 2003.

Akhter, Z.; Begum, J. A.; Banu, L. A.; Alam, M.; Hossain, S.; Amin, N. F.; Uddin, M. \& Yasmin, Q. S. Stature estimation using head measurements in bangladeshi garo adult females. Bangladesh J. Anat., 7(2):101-4, 2009.

Bassey, E. J. Demi-span as a measure of skeletal size. Ann. Hum. Biol., 13(5):499-502, 1986

Bays, H. E.; Chapman, R. H.; Grandy, S. \& SHIELD Investigators' Group. The relationship of body mass index to diabetes mellitus, hypertension and dyslipidaemia: comparison of data from two national surveys. Int. J. Clin. Pract., 61(5):737-47, 2007.

Chiba, M. \& Terazawa, K. Estimation of stature from somatometry of skull. Forensic Sci. Int., 97(2-3):87-92, 1998.

Chumlea, W. C.; Roche, A. F. \& Steinbaugh, M. L. Estimating stature from knee height for persons 60 to 90 years of age. J. Am. Geriatr. Soc., 33(2):116-20, 1985

Coe, T. R.; Halkes, M.; Houghton, K. \& Jefferson, D. The accuracy of visual estimation of weight and height in pre-operative supine patients. Anaesthesia, 54(6):582-6, 1999.

del Sol, M. Cephalic index in a group of Mapuche individuals in the IX Region of Chile. Int. J. Morphol., 23(3):241-6, 2005.

Haboubi, N. Y.; Hudson, P. R. \& Pathy, M. S. Measurement of height in the elderly. J. Am. Geriatr. Soc., 38(9):1008-10, 1990.

Harper, C.; Krill, J.; Raven, D. \& Jones, N. Intracranial cavity volumes: a new method and its potential applications. Neuropathol. Appl. Neurobiol., 10(1):25-32, 1984.

Herout, P. M. \& Erstad, B. L. Medication errors involving continuously infused medications in a surgical intensive care unit. Crit. Care Med., 32(2):428-32, 2004

Ilayperuma, I. On the prediction of personal stature from cranial dimensions. Int. J. Morphol., 28(4):1135-40, 2010.

Ilayperuma, I. Evaluation of cephalic indices: A clue for racial and sex diversity. Int. J. Morphol., 29(1):112-7, 2011.

Kasai, K.; Richards, L. C. \& Brown, T. Comparative study of craniofacial morphology in Japanese and Australian aboriginal populations. Hum. Biol., 65(5):821-34, 1993

Kouno, T.; Katsumata, N.; Mukai, H.; Ando, M. \& Watanabe, T. Standardization of the body surface area (BSA) formula to calculate the dose of anticancer agents in Japan. Jpn. J. Clin. Oncol., 33(6):30913, 2003.

Krishan, K. Estimation of stature from cephalo-facial anthropometry in north Indian population. Forensic Sci. Int., 181(1-3):52.e1-6, 2008.

Kwok, T. \& Whitelaw, M. N. The use of armspan in nutritional assessment of the elderly. J. Am. Geriatr. Soc., 39(5):492-6, 1991.

McCaffery, P. \& Deutsch, C. K. Macrocephaly and the control of brain growth in autistic disorders. Prog. Neurobiol., 77(1-2):38-56, 2005.

Mansur, D. I.; Haque, M. K.; Sharma, K.; Mehta, D. K. \& Shakya, R. Use of head circumference as a predictor of height of individual. Kathmandu Univ. Med. J. (KUMJ), 12(46):89-92, 2014.

Nguyen, A. K. D.; Simard-Meilleur, A. A.; Berthiaume, C.; Godbout, R. \& 
ILAYPERUMA, I.; NANAYAKKARA, B. G. \& PALAHEPITIYA, N. K. Occipito-frontal circumference as a personal stature predictor in a group of Sri Lankan adults. Int. J. Morphol., 35(4):1316-1321, 2017.

Mottron, L. Head circumference in canadian male adults: Development of a normalized chart. Int. J. Morphol., 30(4):1474-80, 2012.

Obikili, E. N. \& Singh, S. P. Secular growth trend in the adult stature of Nigerians. Orient. J. Med., 4:44-7, 1992.

Okupe, R. F.; Coker, O. O. \& Gbajumo, S. A. Assessment of fetal biparietal diameter during normal pregnancy by ultrasound in Nigerian women. Br. J. Obstet. Gynaecol., 91(7):629-32, 1984.

Ormeci, A.R.; Gürbüz, H.; Ayata, A. \& Çetin, H. Adult Head Circumferences and Centiles. J. Turgut Özal Med. Cent., 4:261-64, 1997.

Rabito, E. I.; Vannucchi, G. B.; Suen, V. M. M.; Castilho Neto, L. L. C. \& Marchini, J. S. Weight and height prediction of immobilized patients. Rev. Nutr., 19(6):655-61, 2006.

Rexhepi, A. \& Meka, V. Cephalofacial morphological characteristics of Albanian Kosova population. Int. J. Morphol., 26(4):935-40, 2008.

Saunders, C. L.; Lejarraga, H. \& del Pino, M. Assessment of head size adjusted for height: an anthropometric tool for clinical use based on Argentinian data. Ann. Hum. Biol., 33(4):415-23, 2006.

Venkataraman, R.; Ranganathan, L.; Nirmal, V.; Kameshwaran, J.; Sheela, C. V.; Renuka, M. V., \& Ramakrishnan, N. Height measurement in the critically ill patient: A tall order in the critical care unit. Indian J. Crit. Care Med., 19(11):665-8, 2015.

Williams, C. A.; Dagli, A. \& Battaglia, A. Genetic disorders associated with macrocephaly. Am. J. Med. Genet. A, 146A(15):2023-37, 2008.

Williams, P. L.; Bannister, L. H.; Berry, M. M.; Collins, P.; Dyson, M. \& Dussek, J. E. Gray's Anatomy: The anatomical basis of medicine and surgery. $38^{\text {th }}$ ed. New York, Churchill Livingstone, 2000.

Winter, R. M. \& Baraitser M. London Dysmorphology Database. Oxford, Oxford University Press, 1996.

Wolf, H.; Kruggel, F.; Hensel A.; Wahlund, L. O.; Arendt, T. \& Gertz, H. J. The relationship between head size and intracranial volume in elderly subjects. Brain Res., 973(1):74-80, 2003.

\section{Corresponding author: \\ Professor I. llayperuma \\ Department of Anatomy \\ Faculty of Medicine \\ University of Ruhuna \\ SRI LANKA}

E-mail: iisurani@yahoo.com

Received: 22-05-2017

Accepted: 13-09-2017 